This item was submitted to Loughborough's Research Repository by the author.

Items in Figshare are protected by copyright, with all rights reserved, unless otherwise indicated.

\title{
Bilateral scapular kinematics, asymmetries and shoulder pain in wheelchair athletes
}

PLEASE CITE THE PUBLISHED VERSION

https://doi.org/10.1016/j.gaitpost.2018.07.170

PUBLISHER

(C) Elsevier

VERSION

AM (Accepted Manuscript)

\section{PUBLISHER STATEMENT}

This work is made available according to the conditions of the Creative Commons Attribution-NonCommercialNoDerivatives 4.0 International (CC BY-NC-ND 4.0) licence. Full details of this licence are available at: https://creativecommons.org/licenses/by-nc-nd/4.0/

\section{LICENCE}

CC BY-NC-ND 4.0

\section{REPOSITORY RECORD}

Mason, Barry, Riemer J. Vegter, Thomas A.W. Paulson, Dylan Morrissey, Jan W. van der Scheer, and Vicky Goosey-Tolfrey. 2019. "Bilateral Scapular Kinematics, Asymmetries and Shoulder Pain in Wheelchair Athletes". figshare. https://hdl.handle.net/2134/34125. 


\section{Accepted Manuscript}

Title: Bilateral scapular kinematics, asymmetries and shoulder pain in wheelchair athletes

Authors: Barry S. Mason, Riemer J.K. Vegter, Thomas A.W. Paulson, Dylan Morrissey, Jan W. van der Scheer, Victoria L. Goosey-Tolfrey

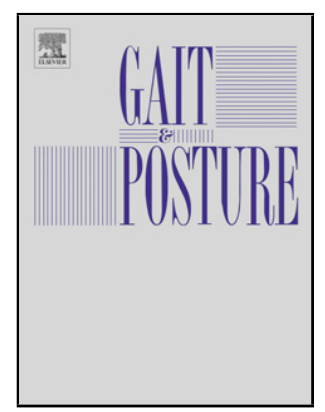

PII: S0966-6362(18)30199-1

DOI:

Reference: https://doi.org/10.1016/j.gaitpost.2018.07.170

To appear in: $\quad$ Gait \& Posture

Received date: $\quad 14-3-2018$

Revised date: $\quad$ 9-7-2018

Accepted date: $\quad$ 19-7-2018

Please cite this article as: Mason BS, Vegter RJK, Paulson TAW, Morrissey D, van der Scheer JW, Goosey-Tolfrey VL, Bilateral scapular kinematics, asymmetries and shoulder pain in wheelchair athletes, Gait and Posture (2018), https://doi.org/10.1016/j.gaitpost.2018.07.170

This is a PDF file of an unedited manuscript that has been accepted for publication. As a service to our customers we are providing this early version of the manuscript. The manuscript will undergo copyediting, typesetting, and review of the resulting proof before it is published in its final form. Please note that during the production process errors may be discovered which could affect the content, and all legal disclaimers that apply to the journal pertain. 


\section{Bilateral scapular kinematics, asymmetries and shoulder pain in wheelchair athletes}

Running head: Shoulder pain in wheelchair athletes

Barry S. Mason, ${ }^{\mathrm{a}}$ Riemer JK. Vegter, ${ }^{\mathrm{b}}$ Thomas AW. Paulson, ${ }^{\mathrm{a}}$ Dylan Morrissey, ${ }^{\mathrm{c}, \mathrm{d}} \mathrm{Jan}$ W. van

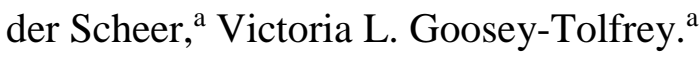

${ }^{a}$ Peter Harrison Centre for Disability Sport, School of Sport, Exercise \& Health Sciences, Loughborough University, UK. *where the study was performed*

${ }^{\mathrm{b}}$ Faculty of Medical Sciences, University of Groningen, The Netherlands.

${ }^{c}$ Sport and Exercise Medicine, Queen Mary University of London, UK

${ }^{\mathrm{d}}$ Barts Health NHS Trust, London, UK

Corresponding author: Dr Barry S. Mason

Peter Harrison Centre for Disability Sport, School of Sport, Exercise \& Health Sciences, Loughborough University, Loughborough, LE11 3TU, UK.

Email: b.mason@lboro.ac.uk Phone: +44 (0) 1509226387

Abstract/manuscript word count: 247/2800

Tables/Figures: 3/3

\section{Highlights:}

- Scapular asymmetries exist during wheelchair propulsion

- Propulsion speed does not alter scapula orientation in trained wheelchair users

- Limited associations between propulsion kinematics and pain in wheelchair athletes 
- Less upwardly rotated scapula was demonstrated in asymptomatic shoulders

- Acromion marker cluster reliably tracks scapula during wheelchair propulsion

\section{Abstract}

Background: Shoulder pain is the most common complaint for wheelchair athletes. Scapular orientation and dyskinesia are thought to be associated with shoulder pathology, yet no previous studies have examined the bilateral scapula kinematics of wheelchair athletes during propulsion. Research question: To examine bilateral scapular kinematics of highly trained wheelchair rugby (WR) players and any associations with self-reported shoulder pain during everyday wheelchair propulsion. Methods: Ten WR players ( 5 with shoulder pain, 5 without) performed $2 \times 3$-minute bouts of exercise in their everyday wheelchair on a wheelchair ergometer at two sub-maximal speeds $\left(3\right.$ and $\left.6 \mathrm{~km} \cdot \mathrm{h}^{-1}\right)$. During the final minute, 3D kinematic data were collected at $100 \mathrm{~Hz}$ to describe scapulothoracic motion relative to each propulsion cycle. Instantaneous asymmetries in scapular orientation between dominant and non-dominant sides were also reported. Differences in scapular kinematics and propulsion asymmetries were compared across shoulders symptomatic and asymptomatic of pain. Results: An internally rotated, upwardly rotated and anteriorly tilted scapula was common during wheelchair propulsion and asymmetries $\leq 14^{\circ}$ did exist, yet minimal changes were observed across speeds. Participants with bilateral shoulder pain displayed a less upwardly rotated scapula during propulsion, however large inter-individual variability in scapular kinematics was noted. Significance: Scapular asymmetries are exhibited by wheelchair athletes during wheelchair propulsion, yet these were not exacerbated by increased speed and had limited associations to shoulder pain. This suggests that propulsion kinematics of highly trained athletes may not be the primary cause of pain experienced by this population. 
Keywords: Wheelchair rugby, injury risk, wheelchair propulsion, biomechanics.

\section{Introduction}

The shoulder has been identified as the most common site of injury in wheelchair athletes [1] with epidemiological studies reporting that up to $72 \%$ of wheelchair athletes experience shoulder pain at some point in their life [2-4]. The most common pathologies associated with shoulder pain in wheelchair athletes are shoulder impingement syndrome, biceps tendinopathy, rotator cuff tears and gleno-humeral instability [3,5]. Muscular imbalances, trunk stabilisation, overuse, and gender are all thought to contribute to shoulder pain $[5,6]$. However, the underlying biomechanical causes and consequences of shoulder pain are not well understood in this population.

In able-bodied $(\mathrm{AB})$ populations, scapular orientation and dyskinesia have been associated with the presence of shoulder pain. Decreased upward rotation and posterior tilting, alongside increased internal rotation of the scapula [7-9] and greater asymmetries between sides [10] have been reported in symptomatic individuals during static and/or planar movements. Although no direct relationships to pain have been made, these scapular orientations are all common to manual wheelchair propulsion $[11,12]$ and are exacerbated as workload increases [13]. The interaction of scapular kinematics, asymmetry and pain therefore requires further investigation to better understand and treat the presentation of wheelchair athletes with shoulder pain.

Previous explorations of scapular kinematics during wheelchair propulsion have largely been unilateral investigations [11-13], yet wheelchair propulsion is predominantly a bilateral activity requiring the coordination of both upper limbs and hence symmetry cannot be assumed 
[14]. Subsequently, bilateral investigations of wheelchair propulsion remain scarce, with the majority having compared kinetic differences [14-16], whilst kinematic comparisons have often been limited to an assessment of propulsion patterns between sides [15,17]. Only Schnorenberg et al. [18] and Soltau et al. [19] have provided detailed analyses of bilateral upper body kinematics during wheelchair propulsion, although these were limited to single-subject case studies [18], paraplegic participants or independent analyses of dominant and nondominant limbs [19]. Despite this, preliminary data suggest that asymmetries exist during wheelchair propulsion $[14,15,17-19]$, hence the need for bilateral investigations where possible. Yet no previous investigations have explored the bilateral scapular kinematics of wheelchair athletes or made any associations to shoulder pain.

In wheelchair sports such as wheelchair rugby (WR), athletes typically cover up to 4.6 $\mathrm{km}$ during competition and perform repeated bouts of high-speed activities, with similar external work performed during training [20]. This work, mainly performed using the relatively small muscle mass of the upper limbs, places large loads and repetitive stress on the shoulder [21]. Although it remains unclear whether this puts athletes at greater risk of experiencing shoulder pain or whether there is a protective effect of being active on the musculoskeletal system $[3,4,22]$. Secondly, WR players spend the majority of their time in a wheelchair designed for activities of daily living (ADL). Therefore, it cannot be assumed that the sporting activities they perform in their sports wheelchair are solely responsible for any inflated injury risk that may exist since the propulsion and transfers they perform during ADL could be the main source of risk.

The aims of the current study were to: i) quantify bilateral scapulothoracic kinematics and propulsion asymmetries of WR players at two speeds reflective of ADL wheelchair propulsion, ii) investigate whether kinematics and the magnitude of asymmetries change with speed, and iii) to explore any differences in scapular orientations and propulsion asymmetries 
between individuals with and without shoulder pain. Success in this work may impact both our understanding of athletic shoulder pain and inform our attempts to prevent and treat these highly debilitating conditions, which impact so profoundly on performance and everyday life while also likely having serious long-term consequences.

\section{Methods}

\section{Participants}

Ten international WR players (age $=34 \pm 5$ years; body mass $=69.5 \pm 5.1 \mathrm{~kg}$ ) who use a manual wheelchair for activities of everyday life provided their written informed consent to participate in the current study. Ethical approval for the procedures was obtained via the local ethical advisory committee. Inclusion criteria required participants to use a manual wheelchair for everyday activities and to have $\geq 3$ years' experience of wheelchair propulsion. All participants were right-hand dominant. Further information about participants characteristics are detailed in Table 1.

\section{INSERT TABLE 1 HERE}

\section{Shoulder pain}

All participants were required to complete an upper extremity pain symptom questionnaire (PSQ), which rates severity on a five-point likert scale $(1=$ 'very mild' to $5=$ 'very severe' $)$ and frequency on a three point scale $(1=$ 'once a week or less' to $3=$ 'more than 3 times a week') of bilateral musculoskeletal upper limb pain in the last 3 months [23]. An overall score for each shoulder was calculated by multiplying the severity and frequency of pain with a score of 15 representing the highest degree of pain possible. 


\section{Protocol}

All experimental trials were performed on a dual-roller wheelchair ergometer (VP Handisport-25, Medical Development HEF Groupe, France). Participants performed all trials in their own ADL, rather than sports, wheelchair. After a 5-minute warm-up participants performed three 'coast-down' trials [24] whereby they accelerated their wheels with three pushes and then sat in a stationary position whilst the wheels decelerated to determine the rolling resistance of the wheelchair-user combination. Two submaximal trials at speeds reflective of everyday wheelchair propulsion were then performed ( 3 and $\left.6 \mathrm{~km} \cdot \mathrm{h}^{-1}\right)$. Each trial lasted 3 minutes and was separated by 2 minutes rest. Individual push phases were defined as the period during which a positive torque was exerted around the wheel, as determined by the ergometer. A positive torque of at least $1 \mathrm{Nm}$ was used to determine the start of the push phase and the time to the start of the next push phase signified a propulsion cycle [16].

\section{Kinematic data}

Kinematic data were collected at $100 \mathrm{~Hz}$ using four Coda CX1 units and Odin software (Codamotion, Charnwood Dynamics Ltd, Leicestershire, UK). Active joint markers were placed on $\mathrm{C7}, \mathrm{T} 8$, incisura jugularis and processus xiphoideus to represent the thorax. Technical cluster markers, consisting of three markers in a rigid formation, were attached to the flat superior surface of the acromion on both sides. Prior to experimental trials, a static trial was captured to determine the locations of the angulus acromialis, trigonum scapulae and angulus inferior in relation to the technical clusters using a stylus to represent both scapulae. All landmarks captured during the static trial were then reconstructed during the experimental 
trials to determine the body segment coordinate systems of the thorax and scapula in accordance with the International Society of Biomechanics (ISB) guidelines [25].

Euler angles were used to describe the orientation of the scapula relative to the thorax (YXZ) and subsequent scapulothoracic motion as internal (+) / external (-) rotation (Y), upward (-) / downward (+) rotation (X) and posterior (+) / anterior (-) tilting (Z). Propulsion cycles within the final minute of each trial were used for analysis and normalised for time at $1 \%$ increments. The mean, minimum, and maximum angles and range of motion (RoM) were calculated for the scapula in each plane across speeds. Asymmetries were defined as the absolute, instantaneous differences in scapular orientation between dominant and nondominant sides.

Following a 20-minute rest period, the protocol was repeated with $7 / 10$ participants. During the rest period all markers were removed, reattached and recalibrated by the same investigator to determine the reliability of the measurements, in particular that of the acromion marker cluster for representing the scapula during wheelchair propulsion.

\section{Statistical Analysis}

All statistical analyses were performed using the Statistical Package for Social Sciences (SPSS Version 23, IBM, New York, USA). Data was checked for normality using ShapiroWilk tests. Scapular kinematic data (mean, minimum, maximum, RoM and asymmetries) were analysed across speeds $\left(3 \& 6 \mathrm{~km} \cdot \mathrm{h}^{-1}\right)$ for both sides (dominant $\&$ non-dominant) using a twoway repeated measures analysis of variance (ANOVA). Effect sizes (ES) defined as the ratio of the mean difference to the pooled standard deviation of the difference were calculated to determine the magnitude of any effects and were classed as trivial $(<0.2)$, small $(0.2-0.6)$, 
moderate (0.6-1.2), large (1.2-2.0) and very large (>2.0) according to previous guidelines [26]. 95\% confidence intervals $(95 \% \mathrm{CI})$ were also calculated to determine the range within which the true ES existed. Reliability of the acromion marker cluster was assessed for both speeds through typical error of the measurement (TE) and intra-class correlation coefficients $\left(\mathrm{ICC}_{3,1}\right)$.

\section{Results}

As demonstrated in Table 1, five participants experienced shoulder pain of which three presented with unilateral and two presented with bilateral pain. The acromion marker cluster demonstrated acceptable reliability for each scapulothoracic motion during both speeds of propulsion, with typical error never exceeding $3.1^{\circ}$ and ICC ranging between $0.87-0.97$ (Table 2).

\section{INSERT TABLE 2 HERE}

Common to both propulsion speeds was an internally rotated, upwardly rotated and anteriorly tilted scapula (Fig. 1). Scapulae moved towards a more internally rotated and less anteriorly tilted position towards the end of the push and early part of the recovery phase. The scapula also upwardly rotates during the push phase and gradually downwardly rotates throughout the recovery phase with a relatively small total excursion in this plane (Fig. 1).

\section{INSERT FIGURE 1 HERE}

Minimal changes in scapular kinematics were observed across speeds, with only a significant increase in maximum internal rotation observed at the highest speed (Table 3 ). Although the magnitude of this difference was moderate $(\mathrm{ES}=0.98), 95 \% \mathrm{CI}$ comfortably spanned zero. No significant differences in scapular kinematics were revealed between dominant and non-dominant sides $(P \geq 0.178)$. However, absolute instantaneous asymmetries 
in mean scapular orientations did exist throughout propulsion but were not significantly affected by speed (Table 3).

\section{INSERT TABLE 3 HERE}

Given the limited effect of speed on scapular kinematics, relationships with shoulder pain were only explored at the fastest speed $\left(6 \mathrm{~km} \cdot \mathrm{h}^{-1}\right)$ as higher loads are likely to be more symptom provoking. The scapular kinematics of asymptomatic individuals $(n=5)$ were compared to those with unilateral $(n=3)$ and bilateral shoulder pain (Table 4). The only notable

difference between these groups was for the mean, minimum and maximum degree of upwards/downwards rotation during propulsion. A less upwardly rotated scapula position was adopted by participants with bilateral shoulder pain (Table 4). This is further emphasised in Fig. 2, where the two individuals with bilateral shoulder pain (participant $1 \& 2$ ), who also reported the highest magnitude of pain overall (Table 1), clearly demonstrated the least upwardly rotated scapular orientation. It was also noticeable from Table 4 and Fig. 2 that large inter-individual variability in scapulothoracic motions existed and that propulsion asymmetries were not influenced by the presence or type (unilateral or bilateral) of pain.

\section{INSERT TABLE 4 \& FIGURE 2 HERE}

\section{Discussion}

This study was the first to explore bilateral scapular kinematics and asymmetries in an athletic wheelchair user population during ADL wheelchair propulsion. It was also the first study that attempted to relate these parameters to shoulder pain. It was revealed that propulsion asymmetries do exist, but scapular orientations and asymmetries were not affected by an increase in speed. Symptomatic individuals with bilateral shoulder pain demonstrated less 
upwards rotation, yet large inter-individual variability in scapular kinematics meant limited and inconsistent relationships to shoulder pain were observed.

During the push phase of the propulsion cycle the scapula move towards a more internally, upwardly rotated and less anteriorly tilted position. Throughout the recovery phase, the scapula maintained an upwardly rotated position, whilst reaching maximal internal rotation and minimal anterior tilt relatively early on. The scapulothoracic motions observed were consistent with previous unilateral observations in everyday wheelchair users [11-13] and also resembled orientations previously associated with shoulder pain in $A B$ populations [7-9,27]. However, previous studies that identified relationships between scapular kinematics and pain in $\mathrm{AB}$ populations did so during tasks around or in excess of $90^{\circ}$ shoulder elevation during static or controlled planar motions [7-9,27]. Given the low shoulder elevation exhibited during wheelchair propulsion it could be suggested that the biomechanics of ADL wheelchair propulsion is a relatively 'low risk' activity for the development of shoulder pain, especially in wheelchair athletes. Risk may simply become elevated due to the high volume of repetitions with which this activity is performed, however further research is required to challenge this assumption.

Perhaps the most notable finding from the current study was that scapular kinematics were almost unaffected by an increase in propulsion speed in these highly trained wheelchair athletes. Only maximum internal rotation increased with speed and the effects of these changes were only moderate and unclear. This contrasts previous observations in everyday wheelchair users, whereby a shift towards increased downward rotation, anterior tilt and protraction were revealed with an increased resistive load [13]. Altered kinematics resulting from increased speed could be potentially dangerous, therefore the fact that minimal changes in scapular kinematics existed could be interpreted as a positive observation and attributed to superior physical conditioning as has previously been proposed $[3,4,22]$, better propulsion skills or 
stability of movement patterns of wheelchair athletes, compared to the everyday users previously investigated [13].

Individuals symptomatic of bilateral shoulder pain did however, demonstrate a less upwardly (more downwardly) rotated scapula than individuals with unilateral shoulder pain and those asymptomatic of shoulder pain by a magnitude greater than the typical error of the measurement. However, establishing whether this decreased upward rotation is a cause of shoulder pain or a compensatory strategy to alleviate shoulder pain remains problematic. At a group level the current results would suggest that the decreased upward rotation demonstrated by individuals with bilateral shoulder pain, who also displayed the greatest magnitude of pain overall, could be a cause of the pain they are experiencing since this motion typically serves to depress the acromion and dynamically reduce subacromial space, which is associated with impingement syndrome [28]. Alternatively at an individual level, not all symptomatic individuals demonstrated this pattern. In particular, participant 8, who reported unilateral shoulder pain, actually displayed the largest degree of upward rotation throughout propulsion (Fig. 3). Subsequently this individual may be adopting this propulsion strategy in an attempt to minimise the pain already experienced. This highlights the potential dangers of utilising grouped data to make associations between kinematics and pain largely owing to the interindividual variability in scapulothoracic motions observed during the current and previous studies [13].

Asymmetries in scapular orientation were also evident throughout propulsion. Since this was the first study to quantify asymmetries in scapular kinematics during propulsion, it is difficult to interpret the magnitude of the bilateral differences observed. Although previous studies have focused on other upper extremity joints, absolute differences of $<5^{\circ}$ have been observed between sides $[19,29]$. The current study revealed mean asymmetries of around $5^{\circ}$ (Table 3), yet large inter-individual variability means individual values are as large as $10-14^{\circ}$. 
Given that scapular RoM is limited in comparison to other upper extremity joints during wheelchair propulsion, these asymmetries could be interpreted as being relatively large. It was also clear that the magnitude of these asymmetries was not significantly affected by increased propulsion speed and relationships to shoulder pain were again limited, even in individuals with unilateral shoulder pain, where greater asymmetries may have been anticipated. Although non-wheelchair specific studies have previously identified relationships between scapulothoracic asymmetry and shoulder impingement syndrome using moiré topography [10] and 3D kinematics [27], the ambiguity between individual asymmetries and shoulder pain currently observed could again suggest that this is not a definite risk factor for the development of pain for wheelchair athletes during ADL wheelchair propulsion and warrants further investigation.

\section{Study Limitations}

A limitation of the current study was that only 5 players experienced shoulder pain and that these were comprised of unilateral and bilateral pain sufferers, which may have skewed the data. Subsequently further research with larger, more homogenous sample sizes would be favourable. Future research examining the bilateral scapular kinematics of wheelchair athletes during maximal effort propulsion in their sports wheelchair would also be warranted. Under these conditions, where load is higher and the wheelchair is configured more for performance rather than comfort like with ADL, the shoulder girdle would be put under greater strain and differences in scapular kinematics may become more evident between symptomatic and asymptomatic populations, although glenohumeral elevation would still remain low. Regardless of this, in order to establish stronger associations as to whether altered scapular kinematics are a cause or consequence of shoulder pain or whether there is no relationship at 
all, longitudinal observations are needed to monitor within-subject adaptations to the development or elimination of shoulder pain. However, kinematics and asymmetries during other ADL tasks, including wheelchair transfers and weight relief, which incur larger shoulder loads and ranges of shoulder movement than propulsion [30] should also be explored.

\section{Conclusions}

The findings of this study demonstrate that scapular asymmetries exist during wheelchair propulsion, yet the orientation of the scapula was relatively unaffected by increased speed in wheelchair athletes and associations to shoulder pain are limited. Only decreased upwards rotation of the scapula appeared related to shoulder pain in bilateral pain sufferers with the greatest magnitude of pain. However, large inter-individual differences in scapular kinematics make associations between kinematics and pain difficult and whether the kinematics are a cause or consequence of the pain during wheelchair propulsion remains unclear.

Conflicts of interest: There are no conflicts of interest to disclose Acknowledgements: The authors would like to thank the Posture and Mobility Group and the Peter Harrison Foundation for funding this research and to the athletes who volunteered to participate. Thanks are also extended to Marika Leving and Dr Bertrand Bru for their assistance with data collection and analysis and to CodaMotion for their technical support throughout. The authors declare no conflicts of interest. 


\section{References}

[1] J. Nyland, S.L. Snouse, M. Anderson, T. Kelly, J.C. Sterling, Soft tissue injuries to USA Paralympians at the 1996 summer games, Arch. Phys. Med. Rehabil. 81 (2000) 368-373.

[2] K.A. Curtis, K. Black, Shoulder pain in female wheelchair basketball players, J. Orthop. Sports. Phys. Ther. 29 (1999) 225-231.

[3] M.A. Finley, M.M. Rodgers, Prevalence and identification of shoulder pathology in athletic and nonathletic wheelchair users with shoulder pain, J. Rehabil. Res. Dev. 41 (2004) 395-402.

[4] H.D. Fullerton, J.J. Borckardt, A.P. Alfano, Shoulder pain: a comparison of wheelchair athletes and nonathletic wheelchair users, Med. Sci. Sports. Exerc. 35 (2003) 1958-1961.

[5] R.S. Burnham, L. May, E. Nelson, R. Steadward, D.C. Reid, Shoulder pain in wheelchair athletes; the role of muscle imbalance, Am. J. Sports. Med. 21 (1993) 238-242.

[6] M. Miyahara, G.G. Sleivert, D.F. Gerrard, The relationship of strength and muscle balance to shoulder pain and impingement syndrome in elite quadriplegic wheelchair rugby players, Int. J. Sports. Med. 19 (1998) 210-214.

[7] A.C. Lukasiewicz, P. McClure, L. Michener, N. Pratt, B. Sennett, Comparison of 3Dimensional scapular position and orientation between subjects with and without shoulder impingement, J. Orthop. Sports. Phys. Ther. 29 (1999) 574-586.

[8] P.M. Ludewig, T.M. Cook, Alterations in shoulder kinematics and associated muscle activity in people with symptoms of shoulder impingement, Phys. Ther. 80 (2000) 276-291.

[9] L.J. Hebert, H. Moffet, B.J. McFadyen, C.E. Dionne, Scapular behaviour in shoulder impingement syndrome, Arch. Phys. Med. Rehabil. 83 (2002) 60-69. 
[10] J.J.P. Warner, L.J. Micheli, L.E. Arslanian, J. Kennedy, R. Kennedy, Scapulothoracic motion in normal shoulders and shoulders with glenohumeral instability and impingement syndrome. A study using Moiré topographic analysis, Clin. Orthop. Relat. Res. 285 (1992) 191-199.

[11] M.M.B. Morrow, K.R. Kaufman, K.N. An, Scapular kinematics and associated impingement risk in manual wheelchair users during propulsion and during a weight relief lift, Clin. Biomech. 26 (2011) 352-357.

[12] K.D. Zhao, M.G. van Straaten, B.A. Cloud, M.M. Morrow, K.N. An, P.M. Ludewig, Scapulothoracic and glenohumeral kinematics during daily tasks in users of manual wheelchairs, Front. Bioeng. Biotechnol. 3 (2015) 1-10.

[13] S. Raina, J.L. McNitt-Gray, S. Mulroy, P.S. Requejo, Effect of increased load on scapular kinematics during manual wheelchair propulsion in individuals with paraplegia and tetraplegia, Hum. Mov. Sci. 31 (2012) 397-407.

[14] W.J. Hurd, M.M. Morrow, K.R. Kaufman, K.N. An, Biomechanic evaluation of upperextremity symmetry during manual wheelchair propulsion over varied terrain, Arch. Phys. Med. Rehabil. 89 (2008) 1996-2002.

[15] B.T. Fay, M.L. Boninger, S.G. Fitzgerald, A.L. Souza, R.A. Cooper, A.M. Koontz, Manual wheelchair pushrim dynamics in people with multiple sclerosis, Arch. Phys. Med. Rehabil. 85 (2004) 935-942.

[16] R.J.K. Vegter, C.J. Lamoth, S. de Groot, D.H.E.J. Veeger, L.H.V. van der Woude, Variability in bimanual wheelchair propulsion: consistency of two instrumented wheels during handrim wheelchair propulsion on a motor driven treadmill, J. Neuroeng. Rehabil. 10 (2013) $1-11$. 
[17] C.L. Stephens, J.R. Engsberg, Comparison of overground and treadmill propulsion patterns of manual wheelchair users with tetraplegia, Disabil. Rehabil. Assist. Technol. 5 (2010) $420-427$.

[18] A.J. Schnorenberg, B.A. Slavens, M. Wang, L.C. Vogel, P.A. Smith, G.F. Harris, Biomechanic model for evaluation of paediatric upper extremity joint dynamicsduring wheelchair mobility, J. Biomech. 47 (2014) 269-276.

[19] S.L. Soltau, J.S. Slowik, P.S. Requejo, S.J. Mulroy, R.R. Neptune, An investigation of bilateral symmetry during manual wheelchair propulsion, Front. Bioeng. Biotechnol. 3 (2015) $1-6$.

[20] J.M. Rhodes, B.S. Mason, T.A.W. Paulson, V.L. Goosey-Tolfrey, A comparison of speed profiles during training and competition in elite wheelchair rugby players, Int. J. Sports. Physiol. Perform. 12 (2017) 777-782.

[21] K. Kulig, S.S. Rao, S.J. Mulroy, C.J. Newsam, J.K. Gronley, E.L. Bontrager, J. Perry, Shoulder joint kinetics during the push phase of wheelchair propulsion, Clin. Orthop. Relat. Res. 354 (1998) 132-143.

[22] E.J. Wylie, T.M. Chakera, Degenrative joint abnormalities in patients with paraplegia of duration greater than 20 years, Paraplegia. 26 (1988) 101-106.

[23] S. van Drongelen, S. de Groot, H.E.J. Veeger, E.L.D. Angenot, A.J. Dallmeijer, M.W.M. Post, L.H.V. van der Woude, Upper extremity musculoskeletal pain during and after rehabilitation in wheelchair-using persons with a spinal cord injury, Spinal. Cord. 44 (2006) $152-159$. 
[24] D. Theisen, M. Franceaux, A. Fayt, A new procedure to determine external power output during handrim wheelchair propulsion on a roller ergometer, Int. J. Sports. Med. 17 (1996) $564-571$.

[25] G. Wu, F.C. van der Helm, H.E.J Veeger, M. Makhsous, P. van Roy, C. Anglin, J. Nagels, A.R. Karduna, K. McQuade, X.G. Wang, F.W. Werner, B. Buchholz, ISB recommendation on definitions of joint coordinate systems of various joints for the reporting of joint motion - part II: shoulder, elbow, wrist and hand, J. Biomech. 38 (2005) 981-992.

[26] A.M. Batterham, W.G. Hopkins, Making meaningful inferences about magnitudes, Int. J. Sports. Physiol. Perform. 1 (2006) 50-57.

[27] E. Turgut, I. Duzgun, G. Baltaci, Scapular asymmetry in participants with and without shoulder impingement syndrome: a 3-dimensional motion analysis, Clin. Biomech. 39 (2016) $1-8$.

[28] B.W. Kibler, P.M. Ludewig, P.W. McClure, L.A. Michener, K. Bak, A.D. Sciascia, Clinical implications of scapular dyskinesis in shoulder injury: the 2013 consensus statement from the 'scapular summit', Brit. J. Sports. Med. 47 (2013) 877-885.

[29] V.L. Goosey, I.G. Campbell, Symmetry of the elbow kinematics during racing wheelchair propulsion, Ergon. 41 (1998) 1810-1820.

[30] S. van Drongelen, L.H.V. van der Woude, H.E.J. Veeger, Load on the shoulder complex during wheelchair propulsion and weight relief lifting, Clin. Biomech. 26 (2011) 452-457. 


\section{Tables and Figures}

Fig. 1. Grouped scapular kinematics normalised (0-100\%) to a whole propulsion cycle at 6 $\mathrm{km} \cdot \mathrm{h}^{-1}$. n.b. Black line represents mean and error bars represent SD; Dashed line denotes end of push phase and transition to recovery phase, estimated from group cycle time data.

Fig. 2. Mean bilateral scapular kinematics of individual participants at $6 \mathrm{~km} \cdot \mathrm{h}^{-1}$. n.b. Dashed line denotes self-reported shoulder pain. 


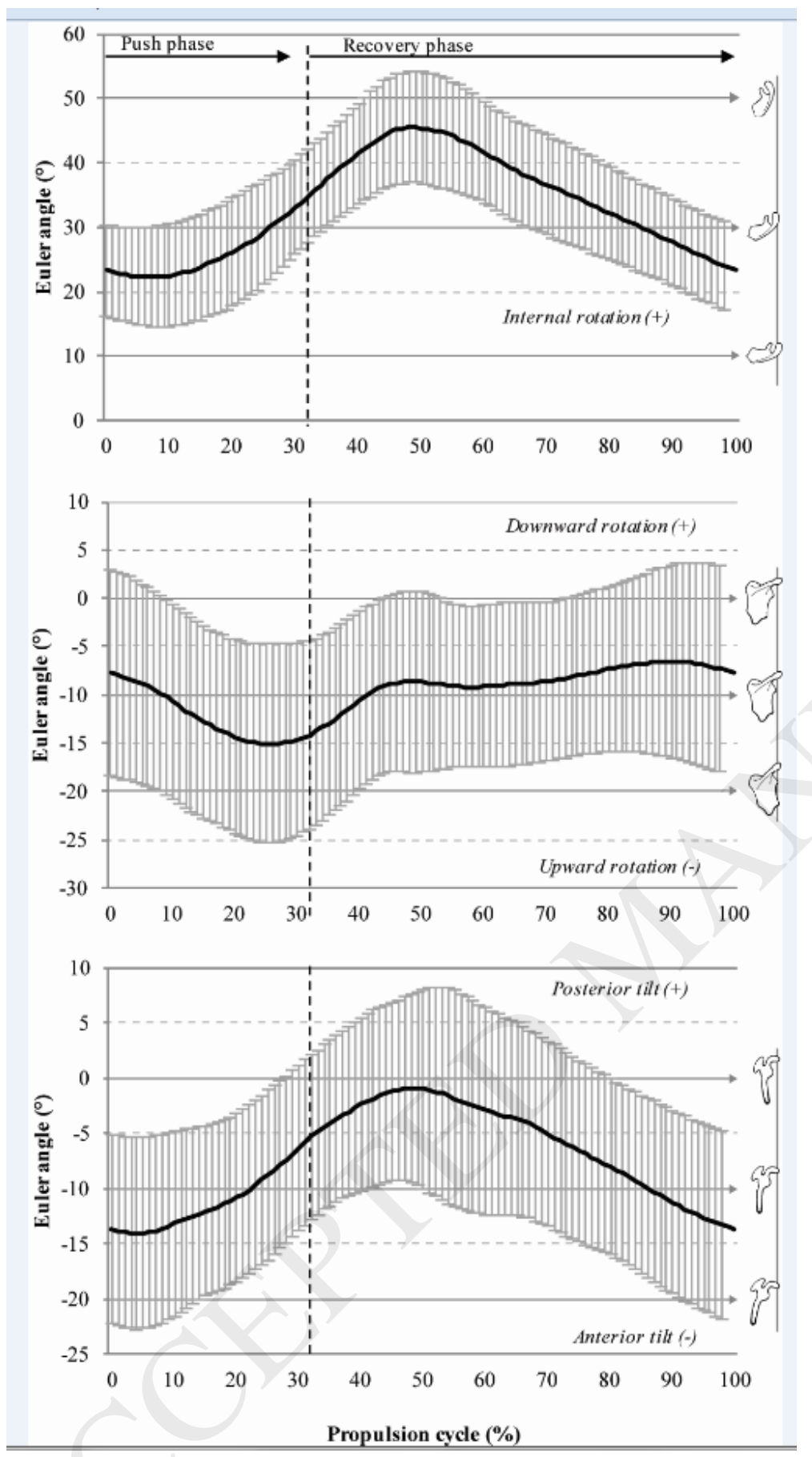




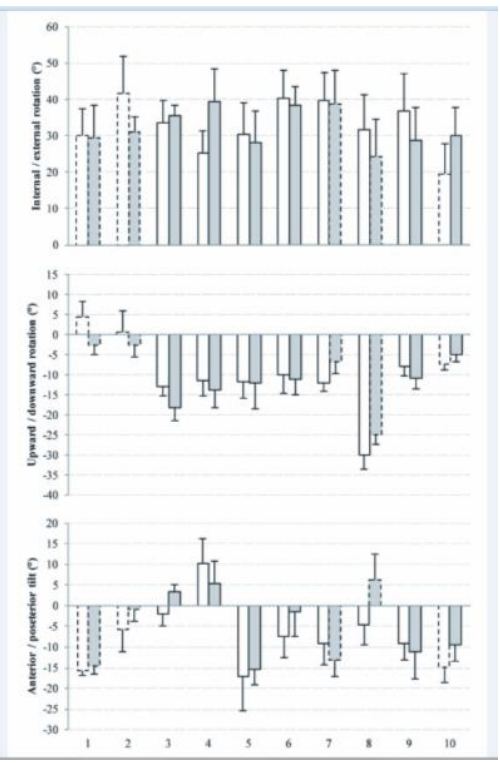


Table 1 Participant characteristics

\begin{tabular}{|c|c|c|c|c|c|c|c|c|}
\hline $\begin{array}{c}\text { Particip } \\
\text { ant }\end{array}$ & $\begin{array}{l}\text { Age } \\
\text { (yrs) }\end{array}$ & $\begin{array}{c}\text { IWRF } \\
\text { classifica } \\
\text { tion }\end{array}$ & $\begin{array}{r}\text { Body } \\
\text { mass } \\
(\mathrm{kg})\end{array}$ & $\begin{array}{c}\text { Wheelchair } \\
\text { mass (kg) }\end{array}$ & $\begin{array}{c}\text { Time as } \\
\text { MWU } \\
\text { (yrs) }\end{array}$ & $\begin{array}{c}\text { PSQ } \\
\text { Shoulder } \\
\text { (Dom/Non- } \\
\text { Dom) }\end{array}$ & $\begin{array}{c}\text { PSQ } \\
\text { Shoulder } \\
\text { (Combine } \\
\text { d) }\end{array}$ & Pain \\
\hline 1 & 34 & 3.0 & 73.6 & 11.8 & 3 & $15 / 15$ & 30 & $\overline{B L}$ \\
\hline 2 & 28 & 0.5 & 66.0 & 15.3 & 9 & $6 / 9$ & 15 & $\mathrm{BL}$ \\
\hline 3 & 34 & 2.5 & 72.2 & 13.6 & 6 & $0 / 0$ & 0 & - \\
\hline 4 & 36 & 2.5 & 72.5 & 12.6 & 13 & $0 / 0$ & 0 & - \\
\hline 5 & 39 & 1.0 & 80.0 & 12.5 & 22 & $0 / 0$ & 0 & - \\
\hline 6 & 31 & 3.0 & 64.1 & 12.5 & 31 & $0 / 0$ & 0 & - \\
\hline 7 & 31 & 1.5 & 67.1 & 11.9 & 9 & $0 / 2$ & 2 & $\mathrm{UL}$ \\
\hline 8 & 28 & 0.5 & 69.2 & 11.8 & 4 & $0 / 2$ & 2 & UL \\
\hline 9 & 36 & 2.0 & 64.9 & 12.5 & 20 & $0 / 0$ & 0 & - \\
\hline 10 & 43 & 2.0 & 65.0 & 10.1 & 26 & $9 / 0$ & 9 & UL \\
\hline $\begin{array}{l}\text { Mean } \\
\text { (SD) }\end{array}$ & $\begin{array}{l}34 \\
(5)\end{array}$ & & $\begin{array}{l}69.5 \\
(5.1)\end{array}$ & $12.5(1.3)$ & $14(10)$ & - & - & \\
\hline
\end{tabular}

n.b. IWRF = International Wheelchair Rugby Federation; MWU = manual wheelchair user; $\mathrm{PSQ}=$ upper-extremity pain symptom questionnaire; Dom = dominant side; Non-Dom = nondominant side; $\mathrm{BL}=$ bilateral; $\mathrm{UL}=$ unilateral; $\mathrm{SD}=$ standard deviation. 
Table 2 Reliability of the acromion marker cluster when determining scapular kinematics at two speeds of wheelchair propulsion.

\begin{tabular}{|l|c|c|c|c|}
\hline & \multicolumn{2}{|c|}{$3 \mathbf{~ k m} \cdot h^{-1}$} & \multicolumn{2}{c|}{ 6 km·h } \\
\hline & TE $\left(^{\circ}\right)$ & ICC & TE $\left(^{\circ}\right)$ & ICC \\
\hline External/internal rotation & 3.1 & 0.87 & 2.4 & 0.93 \\
\hline Upward/downward rotation & 2.6 & 0.90 & 1.6 & 0.97 \\
\hline Anterior/posterior tilt & 2.5 & 0.90 & 1.9 & 0.92 \\
\hline
\end{tabular}

n.b. $\mathrm{TE}=$ Typical Error; $\mathrm{ICC}=$ Intraclass Correlation Coefficient 
Table 3 Mean $( \pm$ SD) bilateral scapular kinematics at different propulsion speeds.

\begin{tabular}{|c|c|c|c|c|c|}
\hline & & $3 \mathrm{~km} \cdot \mathrm{h}^{-1}$ & $6 \mathrm{~km} \cdot \mathrm{h}^{-1}$ & Speed & ES $( \pm 95 \% C I)$ \\
\hline \multirow[t]{4}{*}{ Internal rotation $(+)$} & Mean & $29.7(5.5)$ & $32.6(4.8)$ & 0.243 & $0.56(-0.70,1.83)$ \\
\hline & Min & $20.8(5.5)$ & $21.3(6.3)$ & 0.698 & $0.09(-1.16,1.33)$ \\
\hline & Max & $40.7(6.1)$ & $46.5(6.1)$ & 0.008 & $0.95(-0.36,2.26)$ \\
\hline & RoM & $19.9(5.4)$ & $25.2(5.4)$ & 0.096 & $0.98(-0.33,2.29)$ \\
\hline External rotation (-) & Asym & $5.9(4.7)$ & $6.4(4.4)$ & 0.372 & $0.11(-1.13,1.35)$ \\
\hline \multirow[t]{4}{*}{ Downward rotation $(+)$} & Mean & $-10.3(7.3)$ & $-10.3(7.9)$ & 0.993 & $0.00(-1.24,1.24)$ \\
\hline & Min & $-15.1(7.1)$ & $-16.4(8.2)$ & 0.081 & $0.17(-1.07,1.41)$ \\
\hline & Max & $-6.0(7.2)$ & $-5.3(8.4)$ & 0.429 & $0.09(-1.33,1.15)$ \\
\hline & RoM & $9.0(2.5)$ & $11.0(3.5)$ & 0.056 & $0.60(-0.62,1.93)$ \\
\hline Upward rotation (-) & Asym & $2.9(2.7)$ & $4.3(3.1)$ & 0.139 & $0.48(-0.79,1.72)$ \\
\hline \multirow[t]{4}{*}{ Posterior tilt (+) } & Mean & $-6.2(6.7)$ & $-6.3(7.9)$ & 0.898 & $0.01(-1.23,1.25)$ \\
\hline & Min & $-11.8(7.0)$ & $-13.2(8.1)$ & 0.190 & $0.19(-1.06,1.43)$ \\
\hline & $\operatorname{Max}$ & $-0.1(7.8)$ & $0.6(8.6)$ & 0.373 & $0.09(-1.16,1.33)$ \\
\hline & RoM & $11.7(2.2)$ & $13.8(4.4)$ & 0.114 & $0.60(-0.66,1.87)$ \\
\hline Anterior tilt (-) & Asym & $4.6(2.4)$ & $4.6(2.8)$ & 1.000 & $0.00(-1.24,1.24)$ \\
\hline
\end{tabular}

n.b. Min = minimum $;$ Max = maximum $;$ RoM = range of motion $;$ Asym = asymmetry 
Table 4. Mean (SD) bilateral scapular kinematics of wheelchair athletes with different shoulder pain symptoms during propulsion at $6 \mathrm{~km} \cdot \mathrm{h}^{-1}$

\begin{tabular}{|c|c|c|c|c|c|c|c|}
\hline & & $\begin{array}{r}\text { Asymp } \\
\text { (n }\end{array}$ & $\begin{array}{l}\text { omatic } \\
\text { 5) }\end{array}$ & $\begin{array}{l}\text { Sympt } \\
\text { Unilate }\end{array}$ & $\begin{array}{l}\text { matic - } \\
\text { al }(n=3)\end{array}$ & $\begin{array}{l}\text { Sympto } \\
\text { Bilater }\end{array}$ & $\begin{array}{l}\text { latic - } \\
(n=2)\end{array}$ \\
\hline & & Dom & $\begin{array}{l}\text { Non- } \\
\text { Dom }\end{array}$ & Pain & No Pain & Dom & $\begin{array}{l}\text { Non- } \\
\text { Dom }\end{array}$ \\
\hline $\begin{array}{l}\text { Internal } \\
\text { rotation }(+)\end{array}$ & Mean & $\begin{array}{l}33.3 \\
(5.8)\end{array}$ & $\begin{array}{l}34.1 \\
(5.3)\end{array}$ & $\begin{array}{l}27.5 \\
(10.0)\end{array}$ & $\begin{array}{l}33.8 \\
(5.1)\end{array}$ & $\begin{array}{l}35.8 \\
(8.1)\end{array}$ & $\begin{array}{l}30.3 \\
(1.1)\end{array}$ \\
\hline & Min & $\begin{array}{l}22.4 \\
(6.2)\end{array}$ & $\begin{array}{l}24.3 \\
(7.7)\end{array}$ & $\begin{array}{l}13.8 \\
(11.0)\end{array}$ & $\begin{array}{l}21.7 \\
(6.0)\end{array}$ & $\begin{array}{l}22.5 \\
(2.2)\end{array}$ & $\begin{array}{l}20.8 \\
(2.4)\end{array}$ \\
\hline & Max & $\begin{array}{l}46.1 \\
(8.0)\end{array}$ & $\begin{array}{l}46.7 \\
(5.4)\end{array}$ & $\begin{array}{l}44.3 \\
(11.0)\end{array}$ & $\begin{array}{l}48.8 \\
(4.7)\end{array}$ & $\begin{array}{c}51.3 \\
(10.5)\end{array}$ & $\begin{array}{l}41.7 \\
(8.6)\end{array}$ \\
\hline & RoM & $\begin{array}{l}23.7 \\
(5.8)\end{array}$ & $\begin{array}{l}22.5 \\
(8.3)\end{array}$ & $\begin{array}{l}30.5 \\
(4.6)\end{array}$ & $\begin{array}{l}27.2 \\
(3.5)\end{array}$ & $\begin{array}{l}28.9 \\
(8.3)\end{array}$ & $\begin{array}{l}20.9 \\
(11.0)\end{array}$ \\
\hline $\begin{array}{l}\text { External } \\
\text { rotation (-) }\end{array}$ & Asym & 6.3 & 0) & 6.7 & 4.3) & 6.1 & \\
\hline $\begin{array}{l}\text { Upward } \\
\text { rotation (-) }\end{array}$ & Mean & $\begin{array}{l}-10.7 \\
(1.9)\end{array}$ & $\begin{array}{l}-13.2 \\
(3.1)\end{array}$ & $\begin{array}{l}-13.0 \\
(10.3)\end{array}$ & $\begin{array}{l}-15.7 \\
(10.3)\end{array}$ & $2.6(2.6)$ & $\begin{array}{l}-2.6 \\
(0.1)\end{array}$ \\
\hline & Min & $\begin{array}{r}-17.0 \\
(3.4)\end{array}$ & $\begin{array}{r}-20.7 \\
(3.2)\end{array}$ & $\begin{array}{l}-17.0 \\
(11.3)\end{array}$ & $\begin{array}{l}-20.4 \\
(14.1)\end{array}$ & $\begin{array}{l}-6.5 \\
(4.9)\end{array}$ & $\begin{array}{l}-6.9 \\
(1.1)\end{array}$ \\
\hline & Max & $-6.0(2.1)$ & $-7.4(3.4)$ & $\begin{array}{c}-8.8 \\
(10.5)\end{array}$ & $\begin{array}{l}-12.6 \\
(12.2)\end{array}$ & $9.0(1.6)$ & $\begin{array}{c}3.4 \\
(1.4)\end{array}$ \\
\hline & RoM & $\begin{array}{l}10.9 \\
(4.4)\end{array}$ & $\begin{array}{l}13.3 \\
(4.4)\end{array}$ & $8.2(2.1)$ & $7.8(2.1)$ & $\begin{array}{l}15.5 \\
(3.3)\end{array}$ & $\begin{array}{l}10.3 \\
(0.3)\end{array}$ \\
\hline
\end{tabular}




\begin{tabular}{|c|c|c|c|c|c|c|c|}
\hline Downward & Asym & \multicolumn{2}{|c|}{$4.0(4.2)$} & \multicolumn{2}{|c|}{$4.3(1.6)$} & \multicolumn{2}{|c|}{$5.1(1.6)$} \\
\hline \multirow[t]{4}{*}{$\begin{array}{l}\text { Anterior tilt } \\
(-)\end{array}$} & Mean & $\begin{array}{l}-5.1 \\
(10.1)\end{array}$ & $-3.8(9.1)$ & $\begin{array}{c}-7.3 \\
(11.7)\end{array}$ & $\begin{array}{l}-7.6 \\
(2.7)\end{array}$ & $\begin{array}{l}-10.7 \\
(6.9)\end{array}$ & $\begin{array}{l}-7.8 \\
(9.5)\end{array}$ \\
\hline & Min & $\begin{array}{l}-12.7 \\
(12.2)\end{array}$ & $\begin{array}{l}-10.7 \\
(10.3)\end{array}$ & $\begin{array}{l}-14.8 \\
(8.6)\end{array}$ & $\begin{array}{l}-15.2 \\
(3.1)\end{array}$ & $\begin{array}{l}-16.2 \\
(2.5)\end{array}$ & $\begin{array}{l}-12.0 \\
(9.0)\end{array}$ \\
\hline & Max & $\begin{array}{c}3.5 \\
(10.3)\end{array}$ & $3.2(8.7)$ & $\begin{array}{c}-0.5 \\
(12.0)\end{array}$ & $\begin{array}{l}-0.3 \\
(3.1)\end{array}$ & $\begin{array}{l}-5.4 \\
(11.0)\end{array}$ & $\begin{array}{c}-4.2 \\
(11.0)\end{array}$ \\
\hline & RoM & $\begin{array}{l}16.2 \\
(6.8)\end{array}$ & $\begin{array}{l}13.9 \\
(4.7)\end{array}$ & $\begin{array}{l}14.3 \\
(3.5)\end{array}$ & $\begin{array}{l}14.9 \\
(1.4)\end{array}$ & $\begin{array}{l}10.8 \\
(8.5)\end{array}$ & $\begin{array}{c}7.8 \\
(2.1)\end{array}$ \\
\hline $\begin{array}{l}\text { Posterior tilt } \\
(+)\end{array}$ & Asym & & $2.0)$ & & & & \\
\hline
\end{tabular}

n.b. Min = minimum $;$ Max = maximum $;$ RoM = range of motion $;$ Asym = asymmetry , Dom $=$ dominant side; Non-Dom $=$ non-dominant side; Pain $=$ side experiencing pain No pain = side not experiencing pain 